\title{
A Modulatory Proctolin-Containing Neuron (MPN). II. State-Dependent Modulation of Rhythmic Motor Activity
}

\author{
Michael P. Nusbaum ${ }^{\mathrm{a}}$ and Eve Marder \\ Department of Biology, Brandeis University, Waltham, Massachusetts 02254
}

\begin{abstract}
The effects of stimulating the modulatory proctolin-containing neurons (MPNs) on the pyloric rhythm of the stomatogastric ganglion of the crab, Cancer borealis, were compared with those produced by exogenously applied proctolin. The effects of both MPN stimulation and proctolin applications depend on the preceding physiological state of the preparation. Both treatments increase the pyloric cycle frequency dramatically in preparations that are slowly cycling, but they have little or no effect on pyloric cycle frequency in preparations that are already rapidly cycling. MPN and proctolin produce maximal pyloric cycle frequencies of about $1.2 \mathrm{~Hz}$, although much faster pyloric frequencies are possible. MPN stimulation and proctolin applications affect the number of impulses fired in each burst by pyloric network neurons. MPN's excitatory actions are longer lasting when a preparation is active than when it is quiescent before stimulation. These data suggest that many of MPN's physiological actions result from its release of proctolin. Small unitary postsynaptic potentials evoked by MPN stimulation in the lateral pyloric neuron may indicate the presence of a second neurotransmitter in MPN.
\end{abstract}

How neural networks are influenced by neurally released peptide modulators is not well understood. Partly this reflects the paucity of well-defined neuronal systems with identified peptidergic neuronal inputs amenable to detailed physiological analysis. To date, most detailed studies employing cellular techniques have relied upon exogenously applied peptides and have focused upon the effects of peptides on individual ionic currents (e.g., Dunlap and Fischbach, 1981; Colombaioni et al., 1985; Berladetti et al., 1987; Levitan et al., 1987; Brown, 1988; Kirk et al., 1988). Some progress has been made in describing the effects of exogenously applied peptides on neural networks (Dekin et al., 1985; Kuhlman et al., 1985; Hooper and Marder, 1987; Li and Calabrese, 1987; Sossin et al., 1987; Heinzel and Selverston, 1988). However, the complexity of neural tissue, and the prevalence of colocalization of transmitters and peptides, makes it imperative to study the physiological actions of peptides released from neurons, as many important dynamics of peptide action may not be seen in studies of exogenously applied peptides. The pair of modulatory proctolin-containing neurons

\footnotetext{
Received Aug. 15, 1988; revised Oct. 18, 1988; accepted Oct. 19, 1988.

We thank Mr. Michael O'Neil for providing invaluable technical assistance. Supported by NRSA NS-07446 (M.P.N.) and NS-17183.

Correspondence should be addressed to Dr. Eve Marder at the above address

" Present address: Department of Biology, San Francisco State University, 1600 Holloway Ave., San Francisco, CA 94132.

Copyright (C) 1989 Society for Neuroscience $0270-6474 / 89 / 051600-08 \$ 02.00 / 0$
}

(MPNs) described in the preceding paper (Nusbaum and Marder, 1989) allow us, for the first time, to compare directly the effects of a proctolin-containing neuron with those of exogenously applied proctolin on a relatively simple neural network, the pyloric system of the crab, Cancer borealis.

The comparison of neurally released peptide to exogenously applied peptide is especially interesting in the case of proctolin and the pyloric rhythm because previous work by Hooper and Marder (1987), using the lobster Panulirus interruptus, showed several interesting features regarding proctolin's effects in this system. First, although the pyloric rhythm can be active at frequencies as high as $3 \mathrm{~Hz}$ without losing its essential character (Marder and Meyrand, 1988), the maximal frequency of the pyloric rhythm in proctolin is about $1-1.2 \mathrm{~Hz}$ (Hooper and Marder, 1987). Interestingly, despite the fact that the anterior burster (AB) neuron, the pacemaker of the pyloric rhythm, can burst as quickly as $2.5 \mathrm{~Hz}$ in proctolin when isolated, the synaptic connectivity of the pyloric network limits the pyloric frequency in proctolin (Hooper and Marder, 1987). The significance of this finding is that if exogenous proctolin is applied to a preparation that is inactive or only generating a slow pyloric rhythm, it has dramatic and robust actions, but its effects are virtually nonexistent if the pyloric rhythm is strongly active before proctolin application. We were interested in determining whether this was also the case for the physiological actions of a proctolin-containing neuron, as this type of neuron would then act to bias the pyloric network to a given frequency but not to excite it regardless of its starting point.

Therefore, we compared the actions of proctolin and MPN stimulation on the pyloric rhythm frequency and the firing patterns of the pyloric network neurons of the crab, Cancer borealis. The results reported here for the effects of proctolin on the pyloric rhythm of the crab are similar to those in the lobster, Panulirus interruptus. The effects of MPN stimulation also show state-dependent actions that are qualitatively similar to those of proctolin. Some of these data have appeared in abstract form (Nusbaum and Marder, 1988b).

\section{Materials and Methods}

Neurophysiological preparations and electrophysiological recording techniques were as described in Nusbaum and Marder (1989). Except where noted, all data were collected from preparations of the crab, Cancer borealis, consisting of the esophageal (OG) and stomatogastric (STG) ganglia plus their connecting and motor nerves. The commissural ganglia (CGs) were connected to the OG and STG, but activity in the CGs was suppressed by chronic incubation of the vaseline-encircled CGs with isotonic sucrose $(750 \mathrm{~mm})$. All experiments were performed with a continuously flowing superfusion system $(6-10 \mathrm{ml} / \mathrm{min})$, cooled to $12-16^{\circ} \mathrm{C}$, that allowed rapid changes of the bath solution. Proctolin (Sigma) was introduced through this system without interrupting the flow of solution. Bath volume was $15-20 \mathrm{ml}$. 


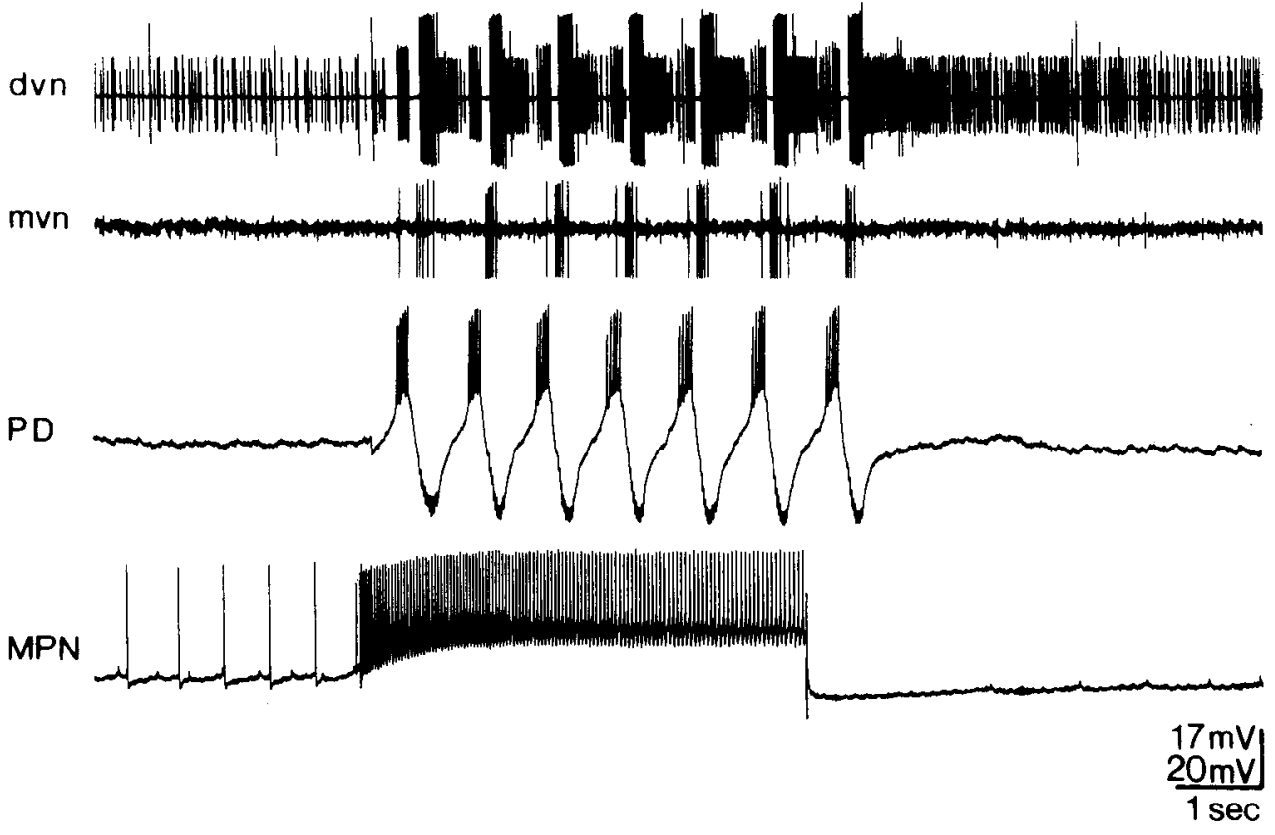

Figure 1. Initiation of the pyloric rhythm by intracellular stimulation of MPN. MPN firing frequency was 20 $25 \mathrm{~Hz}$. The largest spikes in the extracellular dvn recording are from the LP neuron, the medium-sized spikes are from the PD ncurons, and the smallest are from the PY neurons. The rhythmically active spike in the extracellular mvn recording is the IC neuron.

\section{Results}

MPN stimulation can initiate the pyloric rhythm in a preparation showing no rhythmic pyloric activity (Fig. 1), as was previously shown for proctolin (Hooper and Marder, 1984). This figure also serves to illustrate the main features of the pyloric rhythm. During rhythmic pyloric activity, the pyloric dilator (PD) neurons fire in alternation with 3 classes of constrictor neurons. These include the lateral pyloric (LP), seen as the largest unit on the dvn recording, the pyloric (PY), seen on the dvn as small units following the LP, and the inferior cardiac (IC), seen on the mvn recording.

In this paper we compare the effects of MPN stimulation with those of proctolin to attempt to answer 2 questions: (1) Are MPN's effects dependent on the state of excitation of the preparation, as are the effects of exogenously applied proctolin? (2) Are all of MPN's effects likely to be attributable to proctolin?

To this end, we have chosen to focus on the MPN- and proctolin-mediated increases in pyloric cycle frequency and in the activity of the LP and IC neurons. We have chosen these for comparison because in the crab, $C$. borealis, the effects of proctolin and MPN on these features of the pyloric rhythm are particularly robust. The PY neurons also showed increased impulse activity, although not as extensively as the LP and IC neurons. We also report data for the effects of MPN on the $A B$, the pacemaker for the pyloric rhythm, and for the $\mathrm{PD}$ neurons, to which the $\mathrm{AB}$ is electrically coupled. The remaining pyloric network dilator neuron, the ventricular dilator (VD) neuron, only rarely exhibited impulse activity in these preparations and remained subthreshold when the pyloric rhythm was excited by MPN or proctolin.

\section{MPN and proctolin effects on pyloric frequency}

The bar graph in Figure 2 compares the mean pyloric frequencies from 21 experiments in different conditions. When the CGs were left functionally attached to the STG (see Fig. 1, preceding paper), the average pyloric frequency was $1.74 \pm 0.3 \mathrm{~Hz}$ (mean $\pm \mathrm{SD}$ ). When all impulse traffic to and from the (desheathed)
CGs was blocked by placing them in isotonic sucrose, the pyloric cycle frequency decreased dramatically to $0.43 \pm 0.33 \mathrm{~Hz}$ (control). MPN stimulation resulted in a mean pyloric frequency of $0.87 \pm 0.15 \mathrm{~Hz}$. Proctolin applications $\left(10^{-6} \mathrm{M}\right)$ resulted in average frequencies of $0.83 \pm 0.18 \mathrm{~Hz}$. The proctolin and MPN values are not statistically different from each other. However, they are both statistically different ( $p<0.001,2$-tailed Student's $t$ test) from the values for both the control and functionally attached CGs.

The data in Figure 2 illustrate that the maximal frequency possible for the pyloric rhythm is far higher than that produced in the presence of proctolin or during MPN stimulation. Previous work had shown that proctolin has strong excitatory actions when applied to relatively inactive preparations but only

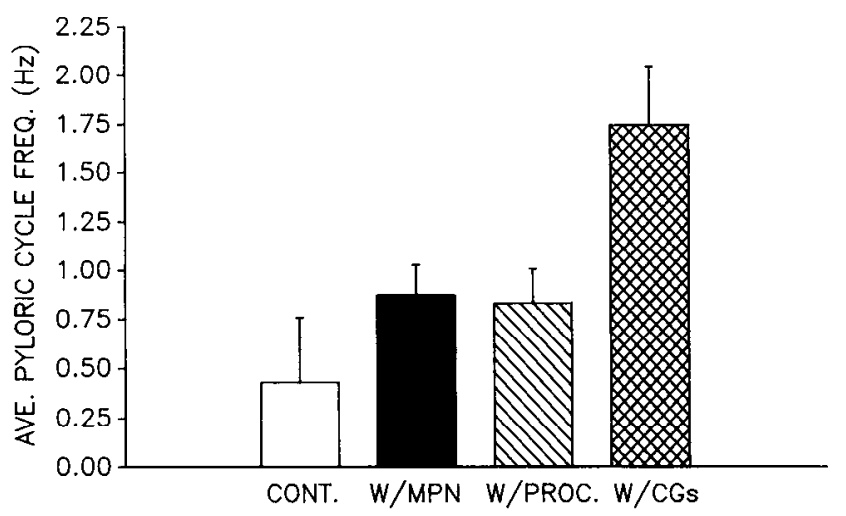

Figure 2. Average pyloric cycle frequency under different conditions. First 3 panels give results for CGs functionally removed by sucrose block. From left to right: saline $(n=21)$, MPN stimulation $(n=9)$, bath-applied proctolin $\left(10^{-6} \mathrm{M} ; n=12\right)$, and with the commissural ganglia (CGs) still functioning ( $n=5$ ). All 3 experimental values were significantly different from controls (Student's 2-tailed $t$ test) at the $p<$ 0.001 level. Similarly, the average frequency with functioning CGs was different from the values for both MPN stimulation and proctolin application at the $p<0.001$ level. There was no difference between the values for MPN stimulation and proctolin application. 


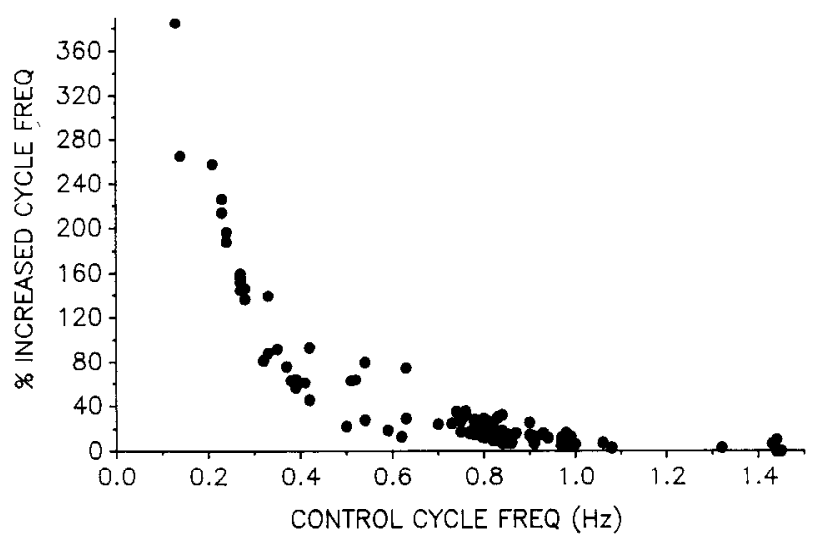

Figure 3. Percentage increase, relative to prestimulus controls, in MPNmediated pyloric cycle frequencies as a function of prestimulus cycle frequency. Each data point is the average of 5-10 cycles. Data include 100 MPN stimulations from 11 different preparations.

minor effects when applied to preparations with rapid pyloric rhythms (Marder et al., 1986; Hooper and Marder, 1987).

Therefore, we were interested to determine whether MPN, like proctolin, would show excitatory actions that depended on the previous physiological state of the preparation. To determine this, we plotted the percentage increase in pyloric cycle frequency as a function of the initial pyloric cycle frequency in Figure 3. This plot shows clearly that MPN had pronounced cxcitatory actions when the preparations were only slowly active under control conditions, but MPN stimulation was virtually without effect on preparations with robust pyloric rhythms before MPN stimulation. In those rhythmic preparations in which the MPNs were spontaneously active, suppressing their activity by hyperpolarizing current injection reduced the pyloric cycle frequency (data not shown). This effect was most pronounced in slowly cycling preparations.

The $A B$ neuron is a conditional oscillator and under many physiological conditions provides timing for the pyloric rhythm
Table 1. Mean number of impulses/burst in pyloric network neurons during MPN stimulation and bath-application of $10^{-6} \mathrm{M}$ proctolin compared with controls

\begin{tabular}{llrlr}
$\begin{array}{l}\text { Neu- } \\
\text { ron }\end{array}$ & Control & W/MPN & Control & W/Proctolin \\
\hline PD & $5.4 \pm 1.8$ & $6.0 \pm 2.0^{a}$ & $5.4 \pm 1.4$ & $6.6 \pm 2.4^{d}$ \\
IC & $2.8 \pm 2.8$ & $7.5 \pm 4.7^{b}$ & $2.1 \pm 2.1$ & $5.4 \pm 2.2^{b}$ \\
LP & $6.1 \pm 3.1$ & $11.9 \pm 3.9^{b}$ & $6.0 \pm 3.8$ & $15.8 \pm 4.3^{c}$
\end{tabular}

Data presented as means \pm SD. Each mean represents data from 3-7 preparations. a.b.c $p<0.05,0.01,0.001$, respectively, relative to controls (2-tailed Student's $t$ test).

${ }^{d} p>0.05$.

There was no statistical difference for any neuron on comparing the mean number of impulses/burst during MPN stimulation versus proctolin application.

(Miller, 1987). In Panulirus interruptus, the $\mathrm{AB}$ neuron is a direct neural target for proctolin, and proctolin increases the amplitude and the frequency of the $A B$ neuron bursts. These excitatory actions are sufficient to explain much of the increase in pyloric frequency and strength produced by proctolin (Hooper and Marder, 1987). Although in the crab we have not yet functionally isolated the $\mathrm{AB}$ neuron from all other pyloric inputs, Figure 4 shows that MPN stimulation increases the amplitude and the frequency of the $A B$ neuron bursts at least when the $A B$ neuron is part of the pyloric network. Thus, the effect of MPN stimulation on pyloric frequency may be partly due to a direct effect of MPN on the $A B$ ncuron.

\section{MPN and proctolin on spikes/burst and burst durations}

MPN and proctolin both increased the number of action potentials/burst in the LP and IC neurons. Data pooled from 7 experiments for these neurons and for the PD neurons are shown in Table 1. During MPN stimulation and proctolin $\left(10^{-6} \mathrm{M}\right)$ application, the average number of impulses/burst in the IC neuron increased 168 and $157 \%$, respectively. Similarly, large increases occurred in the LP neuron. The PD neuron impulse
Figure 4. Enhancement of the frequency and amplitude of $\mathrm{AB}$ neuron oscillations by intracellular stimulation of MPN, during an ongoing pyloric rhythm. MPN firing frequency was 13 Hz.
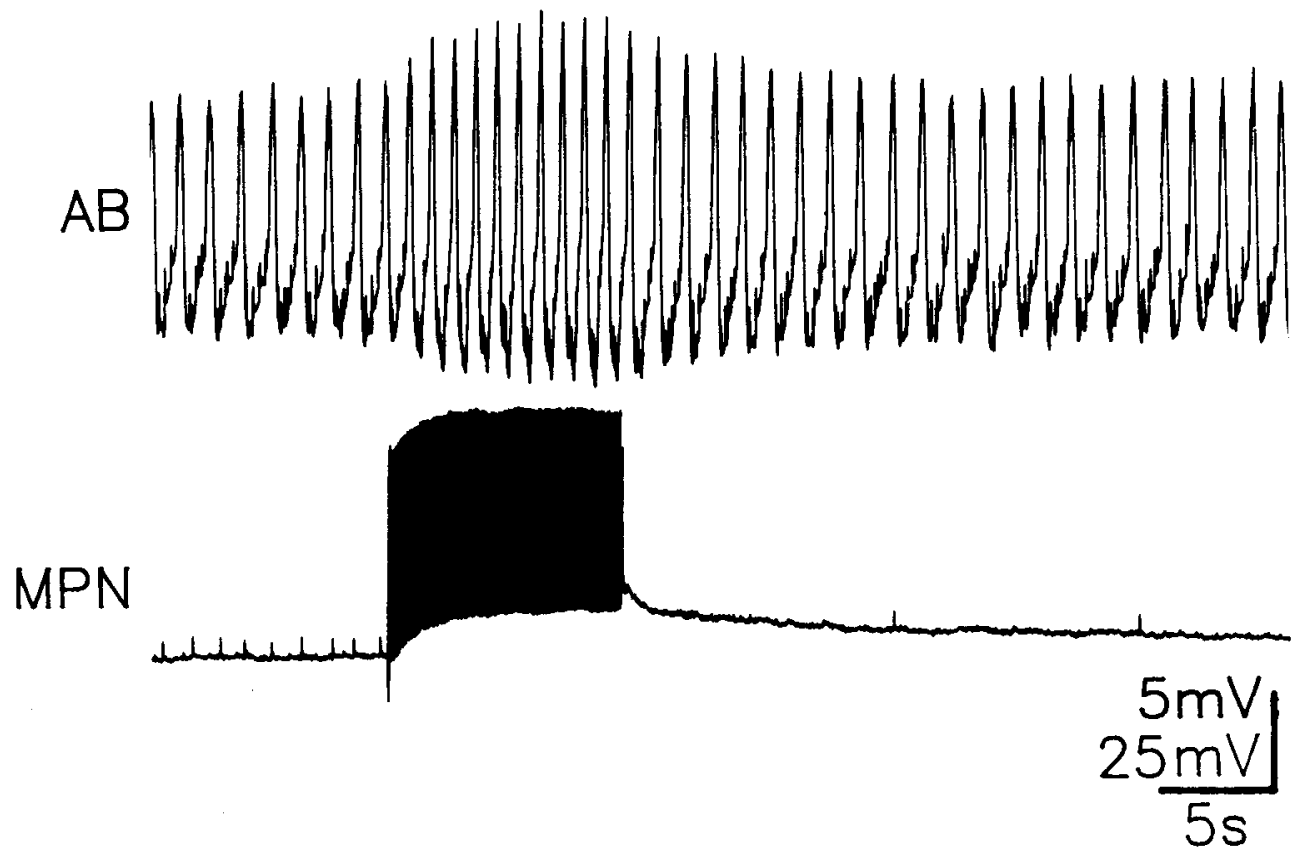


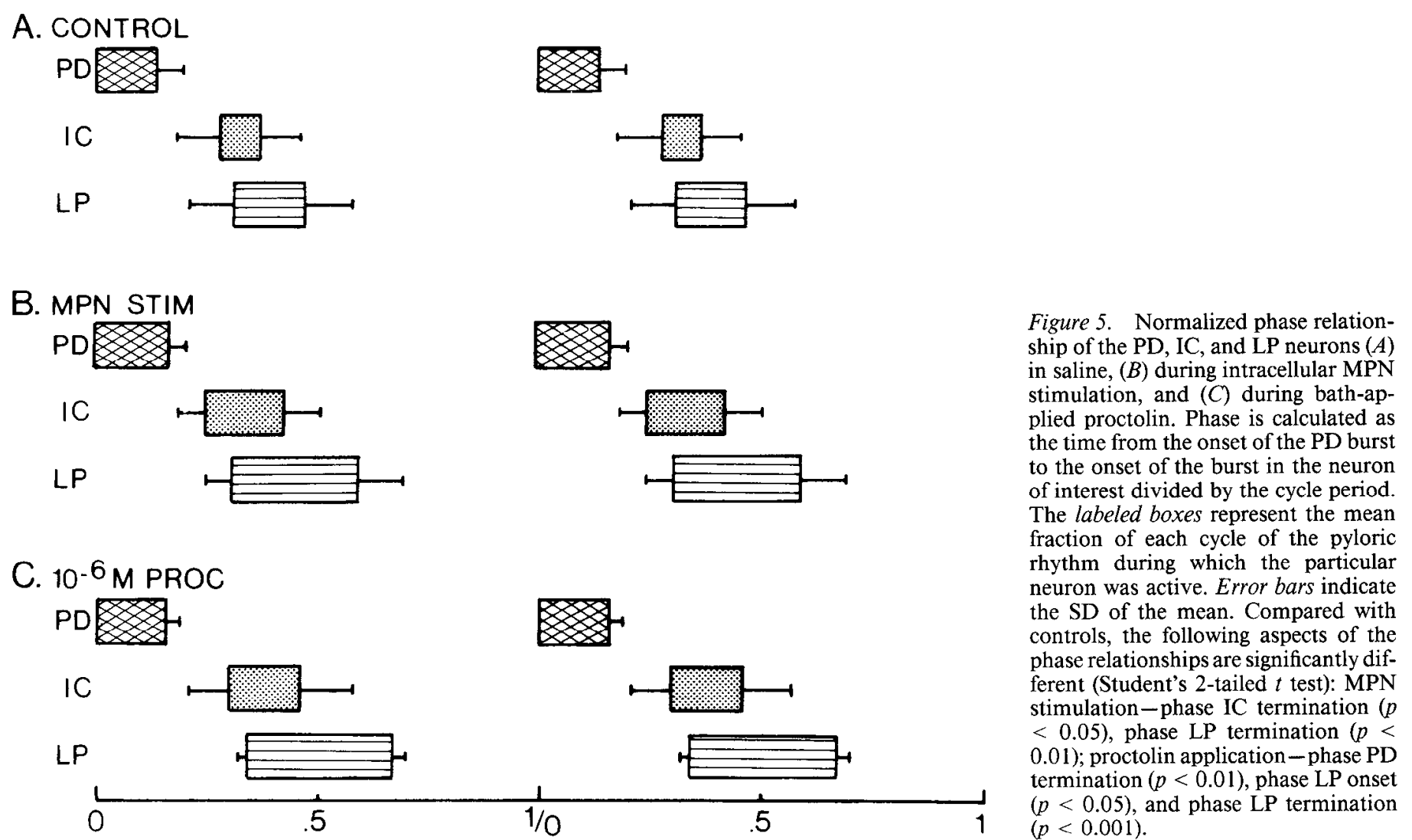

activity was slightly enhanced during MPN stimulation. For all 3 of these neurons, the number of impulses/burst was the same with MPN and proctolin.

Figure $S$ is a plot of the normalized phase of the pyloric cycle in which the PD, IC, and LP neurons fired during control conditions, MPN stimulation, and in the presence of proctolin. The data are pooled from 15 experiments and show that the relative durations of both the LP and IC bursts increased as a result of both MPN stimulation and proctolin application. In each instance, the impulse bursts terminated later than in controls. For the LP neuron, these effects are statistically significant compared with the controls (Fig. 5). The IC neuron duration, however, was significantly longer than control only during MPN stimulation. There was no difference regarding the place during the pyloric cycle where LP and IC fired when comparing MPN stimulation with proctolin application.

\section{Duration of MPN action}

The physiological state of the preparation prior to MPN activation correlated with differences in the degree to which MPN excitation of the pyloric rhythm outlasted the period of MPN stimulation. Figure 6 illustrates that MPN stimulation resulted in enhanced LP and IC activity for at least $10 \mathrm{sec}$ subsequent to the termination of MPN activity. Similar time courses of MPN action can be seen in Figure 4, and were routinely observed in all preparations $(n=10)$ in which there was an active rhythm prior to MPN stimulation. In contrast, when MPN is responsible for initiation of rhythmic pyloric activity (as seen in Fig. 1), the activation of the pyloric circuit does not outlast the stimulation ( $n=4$ preparations).
Many peptidergic neurons contain a non-peptide neurotransmitter in addition to the peptide (Hökfelt et al., 1987). Therefore, we performed experiments to look for physiological actions of MPN that might not be due to proctolin.

Although there are no available blockers of proctolin action, saturating the ganglion with cxogenous proctolin and then stim-

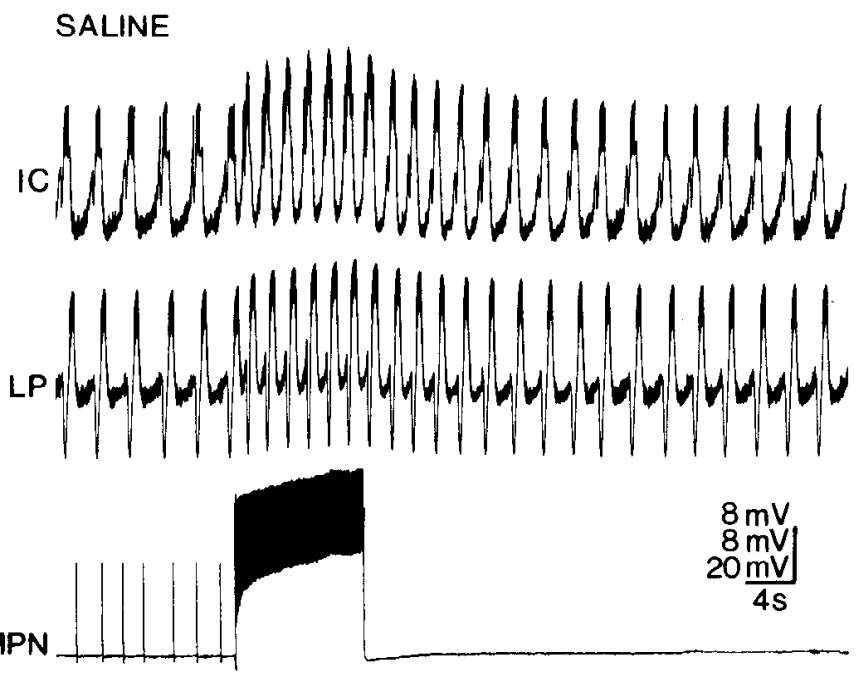

Figure 6. Enhancement of the pyloric rhythm activity in the IC and LP neurons by intracellular stimulation of MPN during saline perfusion. MPN firing frequency was $15 \mathrm{~Hz}$.

\section{Does MPN contain another transmitter?}




\section{A. CONTROL}
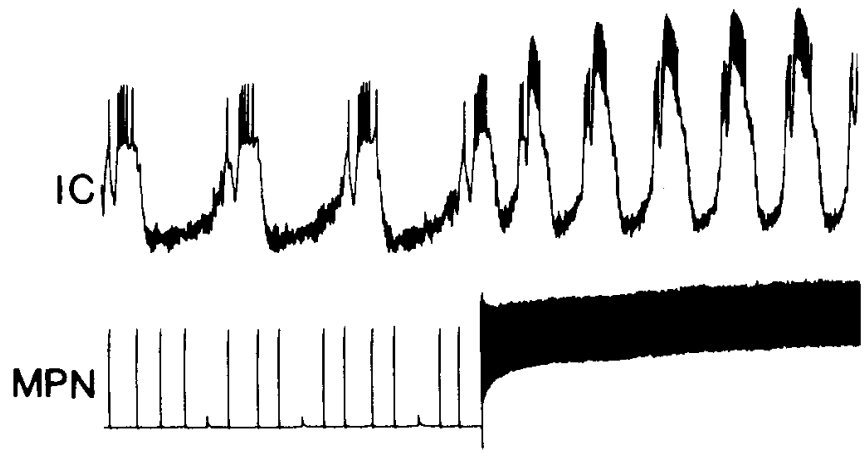

$10 \mathrm{mV}$

$25 \mathrm{mV}$

B. $10^{-6} \mathrm{M}$ PROC

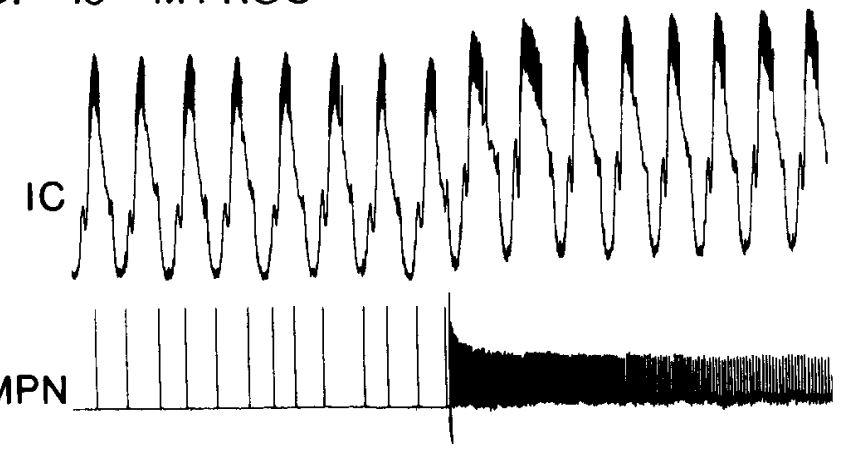

Figure 7. Response of the IC neuron to intracellular stimulation of MPN during $(A)$ saline superfusion and $(B)$ proctolin application. Results in $A$ and $B$ are from the same preparation. Mean pyloric cycle frequency $( \pm \mathrm{SD}):(A)$ control, $0.38 \pm 0.01 \mathrm{~Hz}$; during MPN stimulation $(16 \mathrm{~Hz}), 0.62 \pm 0.02 \mathrm{~Hz} ;(B)$ During proctolin application, $0.78 \pm 0.01$ $\mathrm{Hz}$; with MPN stimulation $(13 \mathrm{~Hz})$ added, $0.83 \pm 0.01 \mathrm{~Hz}$. ulating MPN might uncover an additional effect of MPN that is ordinarily hidden by the strong proctolin-like action of MPN. Therefore, as illustrated in Figure 7, in several experiments we applied high proctolin concentrations $\left(10^{-6}-5 \times 10^{-5} \mathrm{M}\right)$ and stimulated MPN. Proctolin application had no consistent effect on either the membrane potential or, when active, the ongoing firing frequency of MPN. Stimulation of MPN in the presence of proctolin (Fig. 7) failed to reveal an obvious additional component to MPN's action. Moreover, even in the presence of 5 $\times 10^{-5} \mathrm{M}$ proctolin, MPN stimulation produced a slight residual depolarization of the LP and IC neurons. Since proctolin application increases the cycle frequency (Fig. 7), thus decreasing the effect of MPN stimulation (Fig. 3), it is difficult to compare precisely the effects of MPN in the absence and presence of proctolin. Thus, these experiments failed to demonstrate the presence or absence of a non-proctolin effect of MPN stimulation.

In another series of experiments we took advantage of preparations with little or no spontaneous activity to search for unitary postsynaptic potentials associated with MPN activation. Figure $8 A$ shows the results from one such experiment in which, late in the experiment, MPN stimulation failed to activate a pyloric rhythm. Instead, MPN stimulation evoked a slow depolarization of the I.P neuron, with small psps superimposed on the depolarization. Triggering the oscilloscope on the MPN spike (as in Fig. $8 B$ ) revealed that these psps occurred one-forone with the MPN spike. Both the long-lasting depolarization and the psps appear to result from chemically mediated synaptic transmission because they were blocked reversibly by saline containing $20 \mathrm{mM} \mathrm{Co}^{2+}$.

To study these psps further, preparations were placed in high$\mathrm{Ca}^{2+}$ saline to increase the transmitter release from MPN (and hopefully increase the amplitude of the psps) and to increase the threshold of possible intervening neurons (and increase the likelihood that these psps are directed onto the LP neuron).
Figure 8. A, Intracellular stimulation of MPN caused rapid unitary postsynaptic potentials superimposed on a longlasting depolarizing response in LP. LP neuron membrane potential was -120 $\mathrm{mV}$. The LP neuron was impaled with 2 microelectrodes: one for current injection and one for recording membrane potential. MPN firing frequency was $3 \mathrm{~Hz}$. $B$, Superimposed sweeps triggered by MPN impulses. Postsynaptic potentials are elicited in LP (at -55 $\mathrm{mV}$ ) with a fixed latency following each impulse generated in MPN. Results in $A$ and $B$ are from different preparations, both superfused with control physiological saline.
A.
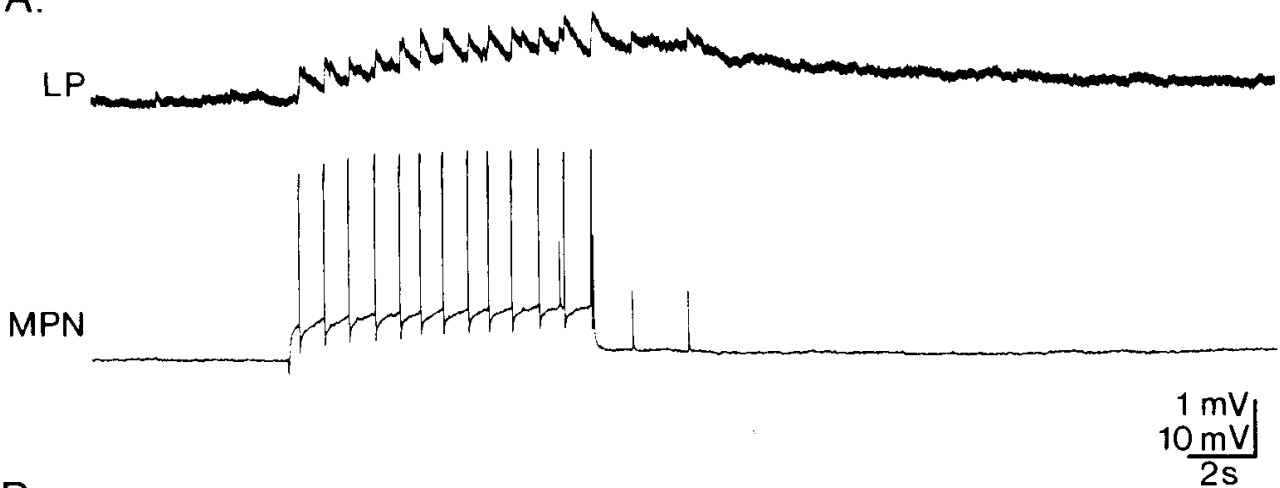

B.
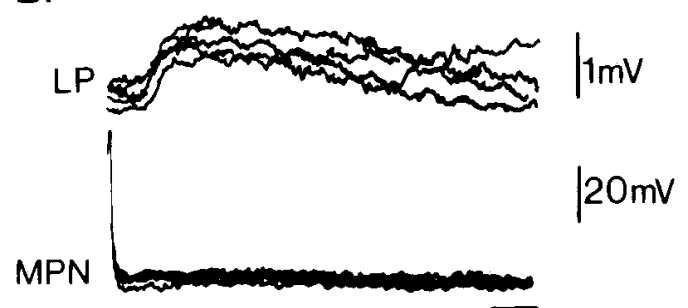

$\overline{20 \mathrm{~ms}}$ 
Figure 9 shows that under these conditions when the LP neuron membrane potential was displaced, the small rapid psp increased in amplitude as the neuron was hyperpolarized and decreased in amplitude with depolarization. The small unitary psp appears to have a reversal potential more positive than -40 $\mathrm{mV}$. It is also interesting that the records in Figure 9 show hints of a slow, longer-lasting depolarizing potential at the more depolarized potentials that is less evident at the more hyperpolarized levels of membrane potential. The extremely small amplitude of these events, even in the presence of high- $\mathrm{Ca}^{2+}$ saline, makes it difficult to study these psps. However, the seemingly conventional nature of the small unitary psps suggests that they may be caused by the action of a non-proctolin transmitter.

\section{Discussion}

\section{Comparing MPN with bath-applied proctolin}

The pyloric rhythms during MPN stimulation and in the presence of bath-applied proctolin were statistically indistinguishable with regard to a number of parameters, including cycle frequency, number of impulses/burst, and burst duration. This reinforces the suggestion made from proctolin immunolabeling of MPN (Nusbaum and Marder, 1988b) that MPN's effects are likely to be at least partly mediated by proctolin. The similarities between MPN and proctolin indicate that bath-applied neuropeptide can be a useful tool for understanding how neurally released peptides affect neural network activity. Additionally, the degree of similarity between MPN and bath-applied proctolin reinforces the conclusion, drawn from extensive studies of pyloric rhythm responses to different bath-applied substances, that apparently hard-wired neural networks can generate a variety of different neural activity patterns (Flamm and HarrisWarrick, 1986; Marder, 1987; Nusbaum and Marder, 1988a).

There are, however, limits to the utility of using bath-application to understand the normal functioning of a neuropeptide. For example, detailed determinations of the time course of the synaptically released peptide are necessary to understand how the peptidergic neuron acts on the neural network, which would not be evident with exogenously applied peptide. Moreover, bath-application does not always so faithfully mimic the effects of a neurally released transmitter. For example, the isolated leech nerve cord produces the swimming motor pattern either when identified serotonin-containing neurons are stimulated or serotonin $\left(>10^{-8} \mathrm{M}\right.$ ) is bath-applied (Willard, 1981; Nusbaum and Kristan, 1986). However, while relatively high doses of serotonin $\left(>10^{-5} \mathrm{M}\right)$ more closely mimic the rapid initiation of the swim motor pattern caused by neuronal stimulation, these doses then cause a hyperpolarization of many swim-related neurons and the swim motor pattern is inhibited (Nusbaum, 1984, 1986).

The experiments reported here show that the IC neuron in C. borealis responds vigorously to proctolin and to MPN, while the VD neuron was not active. In contrast, in $P$. interruptus (Hooper and Marder, 1987) the IC neuron remains silent in proctolin. We think that this reflects the intrinsic differences in the activity of these neurons in the 2 species rather than a fundamental difference in the effects of proctolin in the 2 species.

\section{MPN: multiple transmitters?}

An additional aspect of MPN's effects that was not evident using exogenous proctolin was the occurrence of discrete psps in these same pyloric network neurons in response to MPN stimulation (Figs. 8,9). The 2 distinct postsynaptic effects of MPN observed
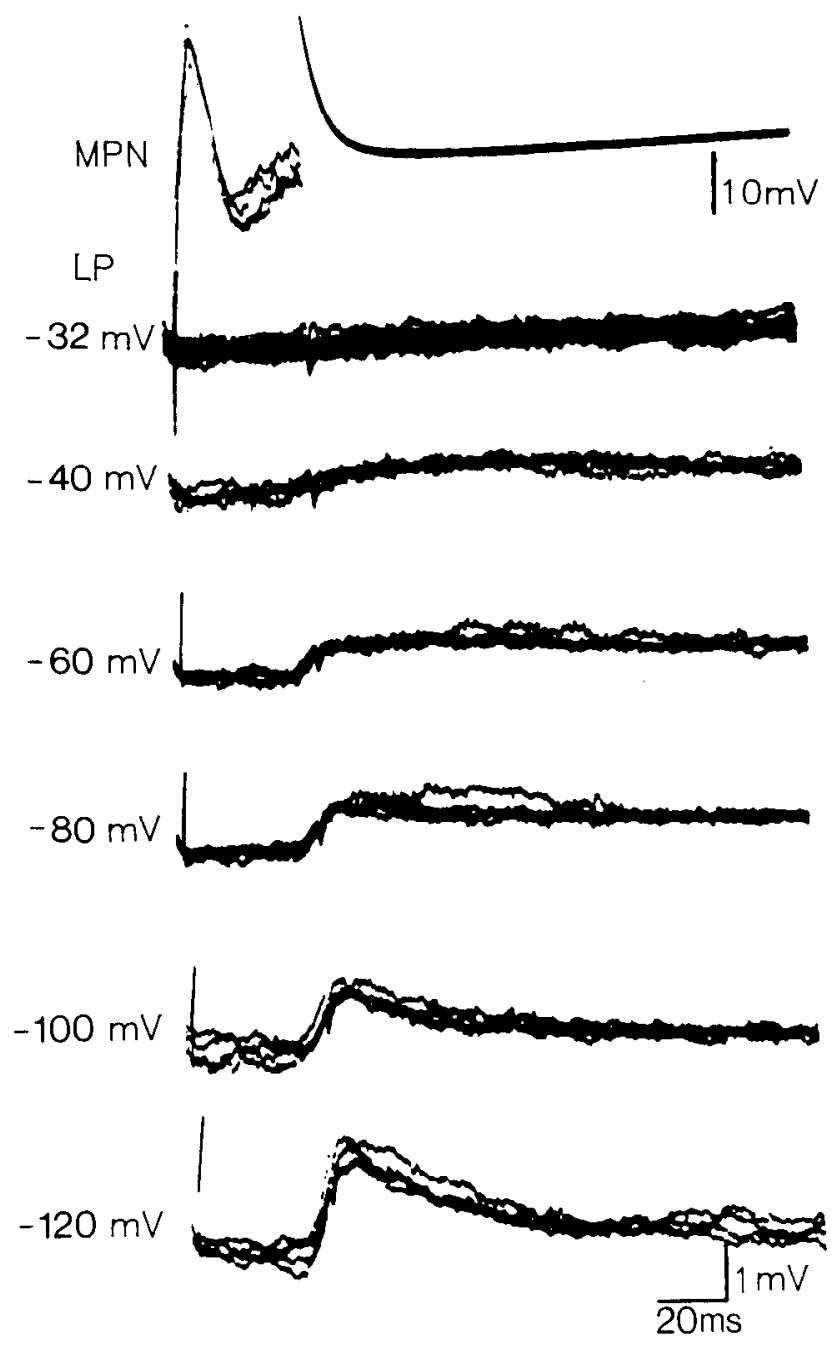

Figure 9. Composite simultaneous intracellular recording of MPN and LP. Each trace shows a series of superimposed sweeps, with each sweep triggered by an impulse elicited in MPN. The stimulus artifact preceding each MPN impulse can be seen on each LP recording. The LP neuron was impaled with 2 intracellular electrodes, one for recording membrane potential and one for current injection. Saline contained 5 -fold elevated levels of $\mathrm{Ca}^{2+}$.

in LP may well reflect the co-release of 2 substances, or they may instead indicate that proctolin interacts with multiple receptors. While it is tempting to propose that the apparently conventional psp caused by MPN reflects a non-peptide-mediated synaptic effect, and that the long-lasting depolarization is due to proctolin release, this conclusion remains premature.

Although termed the modulatory proctolin-containing neuron, MPN may also release one or more additional transmitters/ modulators. Immunocytochemical studies indicate that MPN does not exhibit immunolabeling for the peptides FMRFamide (Marder et al., 1987), red pigment concentrating hormone (Nusbaum and Marder, 1988a), substance P (Goldberg et al., 1988), or small cardioactive peptide B (E. Marder and M. P. Nusbaum, unpublished ubservations). Similarly, MPN does not appear to contain either serotonin or dopamine (Beltz et al., 1984; Marder, 1987; V. Budnik and E. Marder, unpublished observations). Whether MPN does use an additional transmitter, either another peptide or one of the classic, small-molecule transmitters, remains to be determined. One possible candidate is GABA, since GABA-like immunolabeled neurons of the appropriate size are 
found in the OG of the lobster (Cazalets et al., 1987a) and the crab (I. Cournil, M. Nusbaum, E. Marder and M. Moulins, unpublished observations).

Thus far, all the accumulated data are consistent with proctolin being released by impulse activity in MPN. The MPN somata exhibit proctolin-specific immunolabeling (Nusbaum and Marder, 1989), a substance chromatographically indistinguishable from native proctolin is found in the OG and the STG (Marder et al., 1986), and MPN's effects on the pyloric rhythm are nearly identical to those of proctolin (this paper). Future experiments to measure directly proctolin levels in the bath subsequent to MPN stimulation will hopefully confirm this conclusion. This will then enable us to examine whether any part of MPN's long-term effects result from a slow removal or inactivation of proctolin after its release.

\section{Comparison with other identified STG inputs}

In addition to MPN, there are 2 other identified modulators of the pyloric rhythm located in the OG region: the anterior pyloric modulator (APM) (Dickinson and Nagy, 1983; Nagy and Dickinson, 1983; Dickinson et al., 1988) and the pyloric suppressor (PS) neuron (Cazalets et al., 1987b). Although neither of these neurons was studied in $C$. borealis, it is unlikely that either is a homolog of MPN. The PS neuron has the opposite physiological effects from MPN, causing a long-lasting cessation of the pyloric rhythm. APM, like MPN, excites the pyloric rhythm. However, APM has longer-lasting effects than does MPN, and, unlike the case with MPN, all of the pyloric network neurons appear to be targets of APM. Moreover, the axonal projections of APM and MPN are quite different (Nagy and Dickinson, 1983).

\section{State dependent MPN action}

MPN's actions depend on the physiological state of the preparation before its stimulation. When the pyloric rhythm is faster than $1 \mathrm{~Hz}, \mathrm{MPN}$ activation has virtually no effect. However, if the pyloric rhythm is slow and irregular, then MPN activation will produce dramatic and important consequences. Thus, the MPNs have conditional excitatory actions that depend on the physiological state of the target neural network. If sensory stimulation is part of the physiological pathway called into play to activate the MPNs, this would mean that that pathway would be functional only when activated under a certain subset of circumstances, that is, when the pyloric rhythm is relatively inactive. Such state-dependent peptide actions might, in principle, underlie many physiological processes that are notably dependent on the physiological and hormonal state of the animal. These state-dependent actions of MPN can easily be due to MPN-released proctolin, since proctolin has similar conditional actions on the pyloric rhythm (Hooper and Marder, 1987).

It should be stressed that not all substances that excite the pyloric rhythm produce the $1 \mathrm{~Hz}$ frequency characteristic of proctolin. For example, muscarinic cholinergic agonists such as pilocarpine produce pyloric rhythms in the $2 \mathrm{~Hz}$ range (Marder and Meyrand, 1988). In the case of proctolin in the lobster, Panulirus interruptus, the $1 \mathrm{~Hz}$ limitation of pyloric frequency found in proctolin is a consequence of circuit interactions, rather than duc to the ccllular actions of proctolin. Therefore, it will be extremely interesting in the future to determine which pyloric neurons receive monosynaptic inputs from MPN, and whether the saturation of MPN's actions with respect to the pyloric cycle frequency is due to circuit interactions, as with proctolin, or to some property of the neurally released transmitter.

The dependence of the duration of MPN's effects on the state of the pyloric rhythm may be explained by the voltage sensitivity of proctolin's effects (Golowasch and Marder, 1988). In quiescent preparations, MPN activity must be maintained for the pyloric rhythm to continue. In already cycling preparations, MPN enhances the pyloric cycle frequency, but its activity is not necessary to maintain the cycling state, and its effects persist beyond the end of its activity. In the cycling preparations, the rhythmic depolarizations that occur may continue to bring the pyloric targets of MPN into the voltage range where proctolin is maximally effective, in a similar fashion to the voltage-dependent activation of the lamprey spinal cord by $N$-methylaspartate (Sigvardt et al., 1985; Wallen and Grillner, 1987).

In summary, stimulation of the proctolin-containing MPNs evokes actions on the pyloric rhythm that are closely mimicked by proctolin. Interestingly, many of these actions are only seen when the preparation is in a portion of its physiological range. Thus, these data demonstrate that activation of a peptidergic neuron can confer contingent properties on a neural pathway. Hopefully, future studies will allow us to elucidate the detailed cellular and circuit mechanisms that will then enable us to explain exactly how all the properties of MPN's synaptic connections provide the neural substrate for its circuit actions.

\section{References}

Beltz, B., J. S. Eisen, R. E. Flamm, R. M. Harris-Warrick, S. L. Hooper, and E. Marder (1984) Serotonergic innervation and modulation of the stomatogastric ganglion of three decapod crustaceans (Panulirus interruptus, Homarus americanus and Cancer irroratus). J. Exp. Biol. 109: 35-54.

Berladetti, F., E. R. Kandel, and S. Siegelbaum (1987) Neuronal inhibition by the peptide FMRFamide involves opening of $\mathrm{S} \mathrm{K}^{+}$channels. Nature 325 : $153-156$.

Brown, D. (1988) M-currents: An update. Trends Neurosci. 11:294299.

Cazalets, J. R., I. Cournil, M. Geffard, and M. Moulins (1987a) Suppression of oscillatory activity in crustacean pyloric neurons: Implication of GABAergic inputs. J. Neurosci. 7: 2884-2893.

Cazalets, J. R., F. Nagy, and M. Moulins (1987b) Suppressive control of a rhythmic central pattern generator by an identified modulatory neuron in Crustacea. Neurosci. Lett. 81: 267-272.

Colombaioni, L., D. Paupardin-Tritsch, P. P. Vidal, and H. M. Gerschenfeld (1985) The neuropeptide FMRFamide decreases both the $\mathrm{Ca}^{2+}$-conductance and cAMP-dependent $\mathrm{K}^{+}$-conductance in identified snail neurons. J. Neurosci. 5: 2533-2538.

Dekin, M. S., G. B. Richerson, and P. A. Getting (1985) Thyrotropinreleasing hormone induces rhythmic bursting in neurons of the nucleus tractus solitarius. Science 229:67-69.

Dickinson, P. S., and F. Nagy (1983) Control of a central pattern generator by an identified modulatory interneurone in Crustacea. II. Induction and modification of plateau properties in pyloric neurones. J. Exp. Biol. 105: 59-82.

Dickinson, P. S., F. Nagy, and M. Moulins (1988) Control of central pattern generators by an identified neurone in Crustacea: Activation of the gastric mill motor pattern by a neurone known to modulate the pyloric network. J. Exp. Biol. 136: 53-87.

Dunlap, K., and G. D. Fischbach (1981) Neurotransmitters decrease the calcium conductance activated by depolarization of embryonic chick sensory neurones. J. Physiol. (Lond.) 317: 519-535.

Flamm, R. E., and R. M. Harris-Warrick (1986) Aminergic modulation in lobster stomatogastric ganglion. I. Effects on motor pattern and activity of neurons within the pyloric circuit. J. Neurophysiol. 55: 847-865.

Goldberg, D., M. P. Nusbaum, and E. Marder (1988) Substance P-like immunoreactivity in the stomatogastric nervous systems of the crab Cancer borealis and the lobsters Panulinus interruptus and Homarus americanus. Cell Tissue Res. 252: 515-522. 
Golowasch, J., and E. Marder (1988) Proctolin modulates $\mathrm{K}^{+}$and $\mathrm{Cl}^{-}$ currents in the crab STG. Soc. Neurosci. Abstr. 14: 153.

Heinzel, H.-G., and A. I. Selverston (1988) Gastric mill activity in the lobster. III. Effects of proctolin on the isolated central pattern generator. J. Neurophysiol. 59: 566-585.

Hökfelt, T., D. Millhorn, K. Seroogy, Y. Tsuro, S. Ceccatelli, B. Lindh, B. Meister, T. Melander, M. Schalling, T. Barfai, and L. Terenius (1987) Coexistence of peptides with classical transmitters. Experientia 43: 768-780.

Hooper, S. L., and E. Marder (1984) Modulation of a central pattern generator by two neuropeptides, proctolin and FMRFamide. Brain Res. 305: 186-191.

Hooper, S. L., and E. Marder (1987) Modulation of the lobster pyloric rhythm by the peptide proctolin. J. Neurosci. 7: 2097-2112.

Kirk, M. D., R. Taussig, and R. H. Scheller (1988) Egg-laying hormone, serotonin, and cyclic nucleotide modulation of ionic currents in the identified motoneuron B16 of Aplysia. J. Neurosci. 8: 11811193.

Kuhlman, J. R., C. Li, and R. L. Calabrese (1985) FMRFamide-like substances in the leech. II. Bioactivity on the heartbeat system. J. Neurosci. 5: 2310-2317.

Levitan, E. S., R. H. Kramer, and I. B. Levitan (1987) Augmentation of bursting pacemaker activity by egg-laying hormone in Aplysia neuron $\mathrm{R} 15$ is mediated by a cyclic AMP-dependent increase in $\mathrm{Ca}^{2+}$ and $\mathrm{K}^{+}$currents. Proc. Natl. Acad. Sci. USA 84: 6307-6311.

Li, C., and R. L. Calabrese (1987) FMRFamide-like substances in the leech. III. Biochemical characterization and physiological effects. J. Neurosci. 7: 595-603.

Marder, E. (1987) Neurotransmitters and neuromodulators. In The Crustacean Stomatogastric System, A. I. Selverston and M. Moulins, eds., pp. 263-300, Springcr-Verlag, Heidelbcrg.

Marder, E., and P. Meyrand (1988) Chemical modulation of an oscillatory neural circuit. In Neuronal and Cellular Oscillators, J. Jacklet, ed., pp. 295-316, Marcel Dekker, New York.

Marder, E., S. L. Hooper, and K. K. Siwicki (1986) Modulatory action and distribution of the neuropeptide proctolin in the crustacean stomatogastric nervous system. J. Comp. Neurol. 243: 454-467.

Marder, E., R. L. Calabrese, M. P. Nusbaum, and B. Trimmer (1987) Distribution and partial characterization of FMRFamide-like peptides in the stomatogastric nervous systems of the rock crab, Cancer borealis, and the spiny lobster, Panulirus interruptus. J. Comp. Neurol. 259: $150-163$.
Miller, J. P. (1987) Pyloric mechanisms. In The Crustacean Stomatogastric System, A. I. Selverston and M. Moulins, eds., pp. 109-136, Springer-Verlag, Heidelberg.

Nagy, F., and P. S. Dickinson (1983) Control of a central pattern generator by an identified modulatory interneurone in Crustacea. I. Modulation of the pyloric motor output. I. Exp. Biol. 105: 33-58.

Nusbaum, M. P. (1984) Synaptic Activation of Leech Swimming by Identified Serotonin-Containing Neurons, Ph.D. dissertation, University of California, San Diego.

Nusbaum, M. P. (1986) Synaptic basis of swim initiation in the leech. III. Synaptic effects of serotonin-containing interneurones (cells 21 and 61) on swim CPG neurones (cells 18 and 208). J. Exp. Biol. 122: 303-321.

Nusbaum, M. P., and W. B. Kristan, Jr. (1986) Swim initiation in the leech by serotonin-containing interneurones, cells 21 and 61. J. Exp. Biol. 122: 277-302.

Nushaum, M. P., and E. Marder (1988a) A neuronal role for a crustacean red pigment concentrating hormone-like peptide: Neuromodulation of the pyloric rhythm in the crab, Cancer borealis. J. Exp. Biol. 135: 165-181.

Nusbaum, M. P., and E. Marder (1988b) State-dependent modulation of the crab pyloric rhythm by modulatory proctolin-containing neurons. Soc. Neurosci. Abstr. 14: 534.

Nusbaum, M. P., and E. Marder (1989) A modulatory proctolincontaining neuron (MPN). I. Identification and characterization. J. Neurosci. 9: 1591-1599.

Sigvardt, K. A., S. Grillner, P. Wallen, and P. A. M. van Dongen (1985) Activation of NMDA receptors elicits fictive locomotion and bistable membrane properties in the lamprey spinal cord. Brain Res. 336: 390-395.

Sossin, W. S., M. D. Kirk, and R. H. Scheller (1987) Peptidergic modulation of neuronal circuitry controlling feeding in Aplysia. J. Neurosci. 7: 671-681.

Wallen, P., and S. Grillner (1987) $N$-methyl-D-aspartate receptor-induced, inherent oscillatory activity in neurons active during fictive locomotion in the lamprey. J. Neurosci. 7: 2745-2755.

Willard, A. L. (1981) Effects of serotonin on the generation of the motor program for swimming by the medicinal leech. J. Neurosci. 1: 936-944. 